\title{
Antioxidant activity and inhibitory effect of $L$. viridis extract on Fe2+-induced lipid peroxidation in brain homogenates
}

\author{
P Costa 1, S Gonçalves 1, A Romano 1
}

- $\quad 1$ University of Algarve, Faculty of Sciences and Technology and Institute for Biotechnology and Bioengineering (IBB-CGB/UTAD), Campus de Gambelas, Ed. 8, 8005-139 Faro, Portugal

- $\quad$ Congress Abstract

\begin{abstract}
The brain is particularly susceptible to oxidative stress damaging effects due such events as the high consumption of oxygen, limited concentration of antioxidants and a relatively high degree of polyunsaturated fatty acids that are particularly good substrates for peroxidation reactions [1-3]. Oxidative stress could lead to damage biological target molecules, affecting the cellular function and integrity [4]. The ability of natural antioxidants, mainly phenolic compounds, to protect cells from oxidative stress has been previously demonstrated [5]. In this work, the methanol extract from Lavandula viridis L'Hér. (Lamiaceae), a xerophytic aromatic shrub endemic to the south-west Iberian Peninsula [6], was investigated for its effect on deoxyribose degradation, its reducing properties, $\mathrm{Fe}^{2+}$-chelating ability and total phenol content. The capacity of this extract to prevent $\mathrm{Fe}^{2+}$-induced lipid peroxidation in mouse brain (in vitro) was also evaluated. L. viridis extract showed $\mathrm{Fe}^{2+}$ chelating activity, reducing power and the ability to prevent $\mathrm{Fe}^{2+} / \mathrm{H}_{2} \mathrm{O}_{2}$-induced decomposition of deoxyribose in a dose-dependent manner. This extract also revealed a high phenol content $(893.01 \pm 17.09 \mu \mathrm{mol}$ gallic acid equivalents $/ \mathrm{g}$ extract) evaluated by Folin-Ciocalteu method. Moreover, in brain homogenates, the methanol extract of $L$. viridis caused a high decrease in the MDA production in both the basal and the $\mathrm{Fe}^{2+}$-induced lipid peroxidation. The effective protective properties of $L$. viridis could be attributed to its higher phenol content, $\mathrm{Fe}^{2+}$ chelating ability, reducing properties and $\mathrm{HO}$ - radical scavenging ability. The findings suggest that methanol extract from $L$. viridis could be a potential source of natural antioxidants.
\end{abstract}

Acknowledgements: C. Patrícia and S. Gonçalves acknowledge a grant from Portuguese Science and Technology Foundation (FCT, SFRH/BD/63505/2009 and Grant SFRH/BPD/31534/2006, respectively)

References: 1. Sah, R. et al. (2002)J Neurochem 80: 383-391.

2. Shulman, R.G. et al. (2004) Trends Neurosci 27: 489-495.

3. Halliwell, B., Gutteridge, J.M.C. (2007) Free radicals in Biology and medicine, Fourth Edition. Clarendon Press, Oxford Science Publications. Oxford/UK.

4. Britton, R.S. et al. (2002) Int J Hematol 76: 219-228.

5. Stalikas, C.D. (2007)] Sep Sci 30: 3268-3295.

6. Nogueira, J.M.F., Romano, A. (2002) Phytochem Anal 13: 4-7. 